\title{
An evaluation of progress in implementing ecosystem-based management of fisheries in 33 countries
}

\author{
Tony J. Pitcher ${ }^{\mathrm{a}, *}$, Daniela Kalikoski ${ }^{\mathrm{b}}$, Katherine Short ${ }^{\mathrm{c}}$, Divya Varkey ${ }^{\mathrm{a}}$, Ganapathiraju Pramod ${ }^{\mathrm{a}}$ \\ ${ }^{a}$ Fisheries Centre, University of British Columbia, 2002 Main Mall, Vancouver, BC, Canada V6T $1 Z 4$ \\ ${ }^{\mathrm{b}}$ Federal University of Rio Grande, Av. Paulo Gama 110, Porto Alegre, Rio Grande do Sul, 90040-060, Brazil \\ ${ }^{\mathrm{c}}$ WWF-International, Av. du Mont-Blanc, Gland CH-1196, Switzerland
}

\section{A R T I C L E I N F O}

\section{Article history:}

Received 5 March 2008

Received in revised form

11 March 2008

Accepted 6 June 2008

\section{Keywords:}

Ecosystem-based management of fisheries Code of conduct

Performance ratings

Rapfish

\begin{abstract}
A B S T R A C T
The performance of 33 countries was evaluated for ecosystem-based management (EBM) of fisheries in three fields (principles, criteria and implementation) using quantitative ordination including uncertainty. No country rated overall as 'good', only four countries were 'adequate', while over half received 'fail' grades. A few developing countries performed better than many developed nations. Two case studies test the method. In Indonesia, Raja Ampat and Papua, rated similar to the national evaluation, but better performance might follow successful implementation of a planned EBM initiative. A workshop in Australia rated regional fisheries managed by New South Wales 20\% lower for EBM than federally managed fisheries.
\end{abstract}

(c) 2008 Elsevier Ltd. All rights reserved.

\section{Introduction}

There has been a recent trend towards adopting ecosystembased fishery management (EBFM). Although there are a bewildering number of different definitions and shades of meaning of ecosystem-based management (EBM) [1,2], there is widespread agreement about the need to move towards a new fishery management system that recognises explicitly how food web linkages and human interventions may affect sustainability in aquatic ecosystems [3-5]. This paper attempts to evaluate the current status of the implementation of EBM in fisheries worldwide.

Many of the issues now considered vital for EBM are implicit in the FAO (UN) Code of Conduct for Responsible Fisheries [6]. There is an urgent need to manage fisheries in a more ecologically sensitive manner and this is the strength of the overarching concept of EBM. Aiming to operationalise this concept, FAO has also issued guidelines for an ecosystem approach to fisheries [7]. Implementation, however, of the stock-specific 'traffic light'

\footnotetext{
* Corresponding author. Tel.: +1604822 0201; fax: +16048222368.

E-mail addresses: pitcher.t@gmail.com (T.J. Pitcher), Daniela.Kalikoski@fao.org (D. Kalikoski), KShort@wwfint.org (K. Short), divyafish@gmail.com (D. Varkey), prammod.raju@gmail.com (G. Pramod).
}

reference points approach from the FAO guidelines will be difficult until clear and simply measured EBFM indicators for management are agreed by the international community [8,9], a task that has proved more difficult than some envisaged, especially in datapoor fisheries [10,11]. In the meantime, a simple, practical approach published by Ward et al. [12] is easier to adapt as a basis for evaluating status. Many wish to distinguish EBM from EBFM or the ecosystem approach to fishery management (EAFM): as in Ward et al. [12], we use EBM to denote a holistic approach to the management of fisheries, but not the management nor control of pollution, shipping lanes, recreation and other non-fisheries issues.

In fact, the Ward et al. [12] framework is largely based upon the FAO Code of Conduct which, although it originated in the early 1990s before ecosystem thinking became widespread, provides a very robust scheme of key elements such as ecological health, stakeholder involvement and spatial management. As there is already a published analysis of compliance of over 50 countries with the Code of Conduct [13], we were able to use extracts from this material, together with its estimated uncertainties, to score whether the fisheries are managed in accordance with the WWF framework proposed in Ward et al. [12]. In short, we used the scores countries received under the Code of Conduct assessment to evaluate the specific EBM issues identified in the WWF framework. 


\section{Methods}

\subsection{Selection of countries}

Our analysis was based on countries and not on individual fisheries, since under the Law of the Sea Convention (UNCLOS) nation states have a legal responsibility for the control of all fisheries within their EEZs and for their vessels on the High Seas.

We have chosen 33 countries for the main analysis as representing the top $90 \%$ of the world fish catch (see Table 2, the world catch in 1999 is taken as the reference point [13]). In addition, Australia (number 46 in the world catch) is included as a case-study example.

\subsection{Scoring}

Fishery management in the 33 countries was scored against the three main sets of the listed attributes from Ward et al. [12]. These were, overall principles (5 attributes; Table 2, p. 19 in Ward et al.); criteria for success (6 attributes; Table 3, pp. 19-20 in Ward et al.); and implementation steps (12 attributes; Table 6, pp. 50-51 in Ward et al.). Evaluation fields were set up for each of these by assessing material from published country reports on the compliance of over 50 countries with the Code of Conduct for Responsible Fisheries (13) against the criteria detailed in Table 2. Performance scores were allocated on a scale of $0-10$, together with their likely ranges: these were set out on individual scorecards for each country. Scores over of 7/10 and above were considered 'good' and hence likely to lead to reasonably effective implementation of EBM, while scores of $4 / 10$ or less are taken as unacceptable or 'fail grades'.

As a test of the utility and consistency of the method, two additional case studies were undertaken. First, scores for NSW and Australian fisheries were obtained from nine expert fisheries scientists, who participated in an ecosystem-based fisheries workshop $^{1}$ in July 2007 where a scoring framework similar to Table 1 was distributed. Experts canvassed were from New South Wales Fisheries, the Commonwealth Scientific and Industrial Research Organisation (CSIRO) and local universities. Of the nine individual sets of scores, one was discarded as their scores were completely uncorrelated to all the others; the rest exhibited similar ranges and patterns and hence were averaged.

The second test case was in Indonesia. Raja Ampat, an area of over 600 islands covering an area of about $45,000 \mathrm{~km}^{2}$ in the "Coral Triangle" [14], is the site of a recent initiative in EBM set up by The Nature Conservancy, Conservation International and WWF-Indonesia with the local regency government [see 15]. Two of us (DV, TJP) have been involved with field teams of ecologists, social scientists and local universities in ecosystem modelling and analysis of field survey and interview data in support of this project. We have taken the opportunity to use this material to score the current fisheries in Raja Ampat against the criteria in Table 1 . In addition, we estimated what the scores and their ranges might be after a successful implementation of the EBM project [16].

\subsection{Analysis}

For each of the three evaluation fields, raw scores were standardised using fixed reference points of zero and 10/10 and then entered into a non-metric multi-dimensional scaling [17]

1 “Towards Ecosystem-based Fishery Management in New South Wales"; New South Wales Government Fisheries Research Centre, Department of Primary Industry, Cronulla, NSW, Australia, 25-26 July 2007. that incorporates a set of fixed anchor points from the 0 to 10 scoring range. Initial results were rotated to lie congruent with the fixed axis [the 'Rapfish' technique, 18]. The anchored and rotated MDS ordination can be thought of as extracting from the multidimensional raw data (in which each scored attribute represents a dimension) a single-dimension congruent with the original performance scores that maximises the differences among the data points along a scale from $0 \%$ to $100 \%$. A second axis, normal to the first, is also extracted and may be thought of as expressing differing patterns of scores that achieve the same performance rating in different ways. This technique provided performance ratings on a percentage scale for each country, in each of the three evaluation fields. Uncertainty in the resulting ordination was allowed for by entering the upper and lower extreme values for each attribute score into a Monte Carlo simulation [19], which employed 500 iterations to estimate the upper and lower 95\% tiles on the performance rating of each country.

\section{Results}

Scores allocated to each attribute are tabulated in Table 2 . Following the method outlined above, final ordination results are shown in Fig. 1a-c. In these figures two-dimensional ordination plots show the differences in EBM Principles, Indicators and Implementation among the countries. Differences along the $x$-axis relate to the differences in EBM performance; differences in the vertical direction relate to the differences among the countries that are not due to EBM performance.

Fig. 2 shows how different countries score against the EBM performance rating scale (the $x$-axis on Fig. 1). Ratings over $70 \%$ were considered 'good' and likely to lead to reasonably effective implementation of EBM, while performance ratings of $40 \%$ or less represent 'fail grades' that are unlikely to help the implementation of EBM. Scores over $60 \%$ but $<70 \%$ were considered 'acceptable' but in need of improvement.

For the five WWF EBM principles, there are no outstanding good performance ratings, and only six countries (USA, Norway, New Zealand, South Africa, Australia and Canada) have confidence limits that overlap the 'good' $70 \%$ threshold. Three countries (Iceland, Japan and Malaysia) have 'acceptable' scores over 60\%. It is disappointing that almost half (14) of the 33 countries have 'fail grades' (Chile, China, UK, Argentina, Brazil, Pakistan, Indonesia, Morocco, Taiwan, Turkey, Viet Nam, Thailand, Russia and Myanmar).

For the six EBM indicators, four countries (Norway, New Zealand, USA and Iceland) achieve 'good' ratings than span the 70\% threshold; while three countries (Canada, South Africa and Japan) have 'acceptable' performance levels over 60\%. Over half (17) of the 33 countries have 'fail grades' (Mexico, France, Ecuador, UK, India, China, Argentina, Pakistan, Brazil, Indonesia, Morocco, Taiwan, Turkey, Russia, Myanmar, Viet Nam and Thailand).

For the twelve EBM implementation steps, no countries achieve 'good' performance ratings over 70\%; while just two (USA and Canada) have 'acceptable' scores over 60\%. In this evaluation field, two-thirds (21) of the 33 countries have 'fail grades' (Ecuador, Japan, Denmark, Brazil, Argentina, Malaysia, UK, Netherlands, France, Philippines, India, Indonesia, Pakistan, China, Taiwan, Myanmar, Turkey, Viet Nam, Morocco, Thailand and Russia).

Overall scores for EBM (totalled over the three evaluation fields) show that only two countries have 'good' performance ratings over $70 \%$ (Norway and USA), while four countries have 'acceptable' grades between 60\% and 70\% (Iceland, South Africa, Canada and Australia). But about half (16) of the 33 countries have 
Table 1

Scoring framework used in the EBM performance evaluation

- The central focus is maintaining the natural structure and function of ecosystems, including the biodiversity and productivity of natural systems and identified the important species

- Human use and values of ecosystems are central to establishing objectives for the use and management of natural resources

- Ecosystems are dynamic; their attributes and boundaries are constantly changing and consequently, the interactions with human uses also are dynamic

- Natural resources are best managed within a management system that is based on a shared vision and a set of objectives developed amongst stakeholders

- Successful management is adaptive and based on the scientific knowledge, continual learning and embedded monitoring processes

Evaluation Field 2: Six indicators of successful EBM

\begin{tabular}{ll}
\hline Key element & Expression in the fishery (objectives) \\
\hline $\begin{array}{l}\text { The fishery operates in an effective } \\
\text { policy framework }\end{array}$ & $\begin{array}{l}\text { The management system has effective linkages to the } \\
\text { conservation and socio-economic policies and strategies } \\
\text { for the ecosystems where the fishery operates. The } \\
\text { management system appropriately reflects national and } \\
\text { international goals and objectives for conservation and } \\
\text { sustainable use. Subsidies and incentives lead to } \\
\text { improved EBM outcomes in the fishery }\end{array}$ \\
$\begin{array}{l}\text { Social, economic and cultural context of } \\
\text { the fishery is incorporated }\end{array}$ & $\begin{array}{l}\text { Stakeholders are identified from all areas of relevance to } \\
\text { the fishery, and effectively participate in the } \\
\text { management system. The management system and the } \\
\text { implementation of objectives and targets are agreed } \\
\text { across all stakeholders for both stock management and } \\
\text { ecosystem integrity. Institutional changes result in } \\
\text { increased integration and cooperation amongst } \\
\text { stakeholders. Management decisions are based on the } \\
\text { long-term social, economic and cultural benefits of the } \\
\text { society }\end{array}$
\end{tabular}

Mechanisms and enabling processes

Review of regional and national policie and strategies to ensure consistency with EBM principles. Inter-agency procedures are efficient, effective and accountable. New subsidies and incentives reviewed by stakeholders to confirm ecological viability

Procedures are in place for effective participation of stakeholders in all aspects of the management system (such as Management Advisory

Committees, Consultative Councils).

Management procedures are publicly accessible, procicly accessible, and implemented accord to a publicly available plan of the management. Regular review and revision procedures are in place management system. This should include professional assessment
independent of the fishery and independent of the fis
management agency

Ecosystems have been mapped where the fishery operates, and the conservation status of important specie and habitats determined. Habitats, species and ecosystem function vulnerability to fishery impacts have been assessed, and the targets and harvest strategy adjusted to be

precautionary. Assessment of the fishery performance for ecological objectives is undertaken in conjunction with stakeholders, and procedures and outcomes are made public

Agreed objectives, targets, strategies and performance indicators for stock status are developed and implemented. Achievement of fishery objectives is assessed within the fishery management system is assessed within the fishery management system Ecosystem dynamics are fully incorporated into stock assessment models and decisions are cautious. Effective

Stock assessments are timely, open to stakeholder participation, and fully transparent and accountable. Harves strategies are cautious, and wellbuffered against unpredicted failure of assumptions. No take zones' and

marine-protected areas are designed to identify improvements to the

\section{Performance indicators}

Score range

The absence of policy inconsistencie

that will prevent a fishery from

achieving EBM. Inter-agency

cooperation is effective and efficient.

The absence of perverse subsidies and

incentives in the fishery system

The fishery management plan is easily available and is periodically (at agreed regular intervals) open to public review and assessment. Fisheries status reports that include stock and ecosystem performance reports are periodically (at perforily (at public review and evaluation

The ecological integrity of specified sensitive habitats is not declining. Species considered at high or medium risk from fishing (or their surrogates) are identified and their status used as performance indicators. Populations of non-utilised (specified) species vulnerable to fishing impacts are not declining. The bycatch of (specified) protected or otherwise icon species is declining by an agreed proportion each year, or reduced to an agreed level considered acceptable
Target and limit reference points are set at a precautionary level. Limit reference not violated. The age structure and natural distributional range of the population are minimally altered. Stock assessments are open, inclusive and points for stock size and structure are 
Evaluation Field 2: Six indicators of successful EBM

\begin{tabular}{l} 
Key element \\
\hline The resource management system \\
comprehensive and inclusive,
\end{tabular}

Expression in the fishery (objectives)

Mechanisms and enabling processes

Performance indicators

Score $0-10$

Score range comprehensive and inclusive, based on reliable data and knowledge, and uses an adaptive approach

no-take zones are implemented as 'insurance' agains associated non-target catch and bycatch, and wider ecosystem values

The fishery management system is structured using ecological classification (such as ecoregions, bioregions, and habitat classes). Baseline data or benchmarks are available for each performance indicator. Management data are collected for stock management and ecosystem integrity parameters. Arrangements are in place to facilitate the use of data from partner agencies, research collaborators or other sources. Stock and environmenta assessments are conducted in collaboration with fishery operators, partner conservation agencies and other stakeholders e.g. Environmental Non-Government Organisations (ENGOs). The management system responds to new information and data in a timely and effective way. Procedures are in place to recognize and adopt new knowledge or data of importance to ecosystem integrity or stock management. Ecologica risks are assessed in a comprehensive manner, and a precautionary decision-making framework is us precautionary decision-making framework is used to medium risks are iven priority for research funding and implementation

Environmental externalities are

Cross-boundary issues are identified, and addressed within the management system. The long-term dynamics of ecosystems are incorporated into the development of objectives and targets. The management system considers the full range of human uses and system considers the full range of human uses
aspirations for the ecosystems being managed benefit both fisheries management and groad ecosystem goals. Catch levels are et wis are understood and agreed

An ongoing research programme is in place to improve basic knowledge of the life history characteristics of target species, associated and dependent species and the wider ecosystem where the fishery operates. The management system includes monitoring to evalu the status of ecological indicators. Stakeholders participate in management decisions. Ecological risks are continuously reviewed to provide for alteration to the harvest strategy as appropriate

Statutory or other procedures are in place to ensure that fisheries managers are involved in management decisions that may affect the stock or the

ecosystems where the fishery operates. Ecological risks and harvest strategies contain measures to assess and incorporate risks from long-term changes in ecosystems or the effects of their uses. Fishery managers an operators understand and are accountable for their decisions and actions and the impacts of these "in the water participatory. No-take zones are agreed and adequately implemented as part of the fishery management system

The amount and type of fishing effort in (n) each habitat class. The as of bycatch and discards is declining by an agreed proportion each year, or preduced to an agreed level. Bycatch of protected species is declining by an agreed proportion each year, or reduce to an agreed level. Research projects reflect the key ecological issues in the fishery. Comprehensive fishery data monitoring system on targeted species and bycatch is in place. The amount and type of fishing effort on each level of the population of the target species

Critical habitat for the fishery and identified key ecosystem components are protected from water pollution coastal development or other

externalities. Environment-protection strategies take into account the use by fisheries of coastal areas. Allocation of resources for harvest (of exploitable stocks) is made equitably across all legitimate claimants (e.g. requirements of the ecosystem; traditional, subsistence, recreational and commercial fishers) and recognises ecological constraints

Evaluation Field 3: Twelve steps in implementing EBM

\begin{tabular}{lll}
\hline Component step & Involving & Intended outcomes \\
\hline Identify stakeholder community & $\begin{array}{l}\text { Fishery management agencies, conservation agencies, } \\
\text { conservation NGOs, local community groups, scientific/academic } \\
\text { research community, fisher associations or cooperatives, higher } \\
\text { and lower levels of government, fish processing/distribution } \\
\text { groups, Indigenous representatives }\end{array}$ & $\begin{array}{l}\text { A formal network of interested parties with whom the fishery } \\
\text { representatives will participate to prepare and review the } \\
\text { management of the fishery. A transparent and fully accountab } \\
\text { process enabling the participation of all interested parties in the } \\
\text { process of managing the fishery }\end{array}$ \\
$\begin{array}{ll}\text { Conducted by the fishers, research community, fishery managers, } \\
\text { stakeholders and partners. Covers the full area of fishery } \\
\text { operations. The focus is on areas where the fishes are, where they }\end{array}$ & $\begin{array}{l}\text { Maps of the ecosystems throughout the fishery at scales of } \\
\text { resolution consistent with the scale of the fishery. Resolved } \\
\text { habitats at a scale consistent with the potential impacts of the }\end{array}$
\end{tabular}


3. Identify partners and their interests/ responsibilities

Establish ecosystem values

Determine major factors influencing ecosystem values

Establish objectives and targets are fished, and any specific spawning nursery or similar obligate habitats or locations. High resolution is needed in benthic primary producer habitats (such as algal beds, seagrasses, mangroves, coral reefs)

Conservation, environment protection, and coastal planning agencies from all levels of government. Major users and managers of other, possibly co-located, resources (e.g. tourism, mining, oil/gas, transport, and communications). Directly affected local communities

Fishers, research community, fishery managers, stakeholders, partners and the public; designed to identify all major uses and all major natural and ecosystem values throughout the area where the fishery operates

Establishing cause-effect relationships; consider factors both internal and external to the fishery management system. Conducted by the fishers, research community, fishery managers, stakeholders and partners

ERA conducted with participation of all stakeholders and partners, fishers, research community and the fishery manage uses broad multi-disciplinary knowledge base; identifies key areas of uncertainty; open for public scrutiny and review; fully peer reviewed by independent authorities

Fishers, research community, fishery managers, stakeholders and partners. Performance objectives and targets established for: high- and medium-priority risks from the ERA; important aspects of the ecosystems (including protected species, critical habitat); stocks

Fishers, research community, fishery managers, stakeholders and partners. Focus is on identifying appropriate and workable capacity matched to responsibilities for implementing strategies. fishery. Coherent with other ecosystem classification initiatives (at both larger and smaller scales). Major features and exceptions documented (e.g. highly migratory species, oceanographic currents or features, boundary mismatches between taxa). Majo uncertainties identified and documented as guidance for research and investigation programmes

Clarify specific roles and responsibilities for management in the marine environment. Engage with other supportive interests. Promote the opportunity for coordination and integration, improved efficiency across government and better outcomes for marine management, better agency outcomes for lower cost. more accountability in government, more effective long-term solutions to marine ecological problems, and shared approaches to problems held in common

A detailed distributional analysis of the main attributes of the ecosystem where the fishery operates. A clear and agreed expression of the natural and use values, which could include: highly valued habitats; representative areas dedicated as reserves; protected species feeding, breeding, or resting grounds: fishing, spawning grounds, recruitment areas and migration paths for commercial species; highly productive areas such as upwellings; areas popular for recreational fishing or diving; areas used for ports and harbours; areas of high scenic and wilderness amenity; high cultural and historic value; traditional hunting grounds for indigenous peoples; areas of high tourism value; areas used for dumping of dredge wastes, military training, etc. Identified hazards to marine ecosystems and their values from the full range of actual and potential human impacts that occur in the fishery region. These could include: extent of loss/damage of marine habitats; effects of specific fishing gear on benthic habitats; effects of pollution from coastal rivers on inshore habitats; risk of marine pest invasion and disruption to critica habitat or fishing operations; effects of the removal of the biomass of harvested species (in all fisheries) on trophically dependent species

Agreed estimates of high, medium and low risks of the fishery to the ecosystem values identified in step 5 , such as the risk of the fishery to the protected species, and to the ecosystem, habitats, species and genetic diversity

Agreed and shared goals for specific elements of ecosystems. Specific performance objectives and targets for important elements of the ecosystem. Objectives and targets that are comprehensive and precautionary in terms of valued aspects of the ecosystems. Could include: maintaining or recovering population sizes of protected species; maintaining the distribution, area, species diversity and trophic structure of important habitats; reducing fishing effort in specific areas to help protect populations of benthic fauna; increasing the distribution and diversity of benthic fauna considered to be affected by fishing; rehabilitating marine ecosystems to a past (healthier) condition Series of prioritised strategies that define workable activities and responses to achieve specific objectives and targets identified in Step 7. Includes who is responsible, what funds and time frames 
Evaluation Field 3: Twelve steps in implementing EBM

Component step

Strategies designed based on best understanding of the

cause-effect relationships developed in Step 5, and matched to highest-priority needs for corrective actions identified in Step 6

(ERA). Use of incremental strategies where necessary and

unavoidable

are reported and assessed. Strategies could include: declaring network of sanctuary-protected zones; establishing buffer zones, where only specific uses, or types of fishing, are permitted research on improving gear design to reduce impacts on a sensitive habitat, or reduce the bycatch of an important species; improved fishery in reducing pollution from coastal rivers; constructing fish reducing pollution from coastal rivers, construeting fish escapement panels in trawl type and size of fish, or to reduce overall fish bycatch, implementing andustry code of practice to reduce risks of bait discal bird populations

Design information system, including monitoring

Fishers, research community, fishery managers, stakeholders and partners. Focus is on capture of appropriate data/information to determine if strategies are working as expected; objectives and targets are being achieved; cause-effect models are correct; fishery impacts are being reduced. Collaboration and contributions from partners identified

Establish research and information needs and priorities

Fishers, research community, fishery managers, stakeholders and partners. Focus is on identifying specific high-priority areas of uncertainty, and on quality science outcomes, for both stock and ecosystem issues. Collaboration and contributions from partners identified. Research strategies are fully peer reviewed or independently audited

Design performance assessment and review processes

Fishers, research community, fishery managers, stakeholders and partners. Focus is on a process that is participatory and inclusive. The locations, timing and resourcing enables partner and stakeholder participation in reviews of performance of the fishery in relation to stock and ecosystem values. Performance outcomes peer reviewed by independent authorities

Prepare education and training package for fishers
Fishers, fishery managers, extension experts and stakeholders and partners
Efficient and effective fishery information system that provides data and information on stock and ecosystem performance (additional to information needed for stock management); identifies specific effects of fishery strategies on ecosystem values. Could include: Periodic mapping of important habitat distributions; population census of important protected species; species diversity in fished habitats; distribution of fishing effort by gear types and fine spatial scale; size/age classes in harvested species; species diversity in closed areas

Comprehensive research programmes targeted at resolving key ecosystem and stock issues in the fishery. Could include: habitat mapping; impact of fishing on specific habitat types; effects of coastal development on recruitment of harvested species; desig of monitoring programmes to resolve important changes in habitats; biological data of key species (both utilised and nonutilised); determining the dietary preferences of harvested species and their major predators: species conces of harvested species and their major predators; species composition

Periodic (but regular) forum for discussion, review and assessment of fishery performance by partners, stakeholders and the public. Periodic (but regular) forum for review, assessment the public. Penic (but regular) forum for review, assessment stakeholders and

Outreach programme to provide training and support for fishers about new fishery management, ecosystem or other EBM initiatives, and provide local technical support for assessment and resolution of ecosystem issues

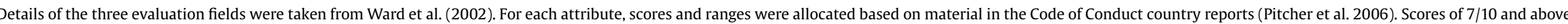
were considered "good"; scores of 4/10 and below represented poor or "fail" grades. 


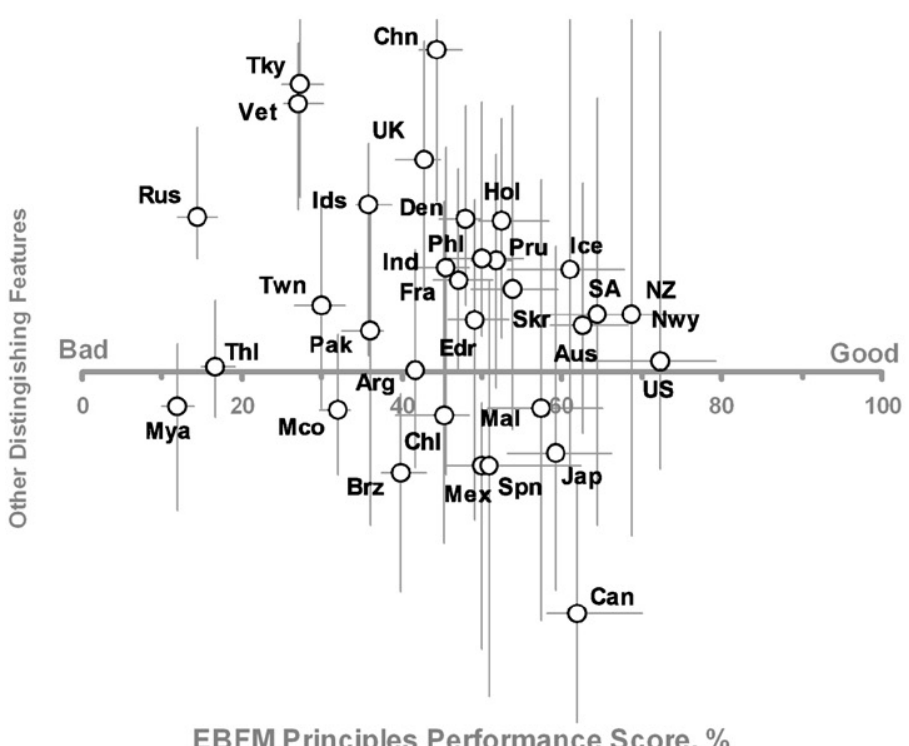

EBFM Principles Performance Score, \%

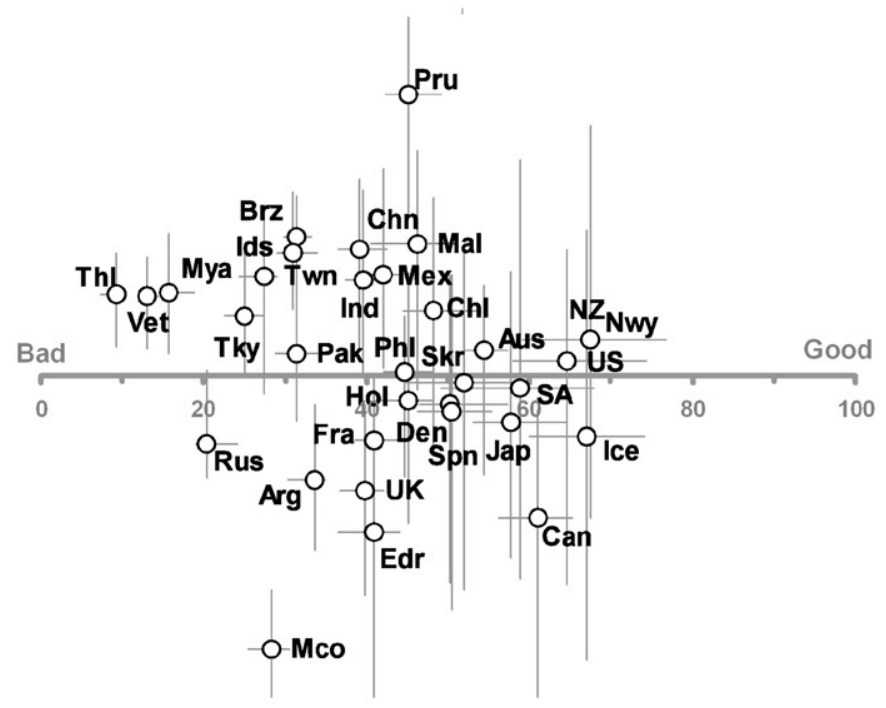

EBFM Indicators Performance Score, \%

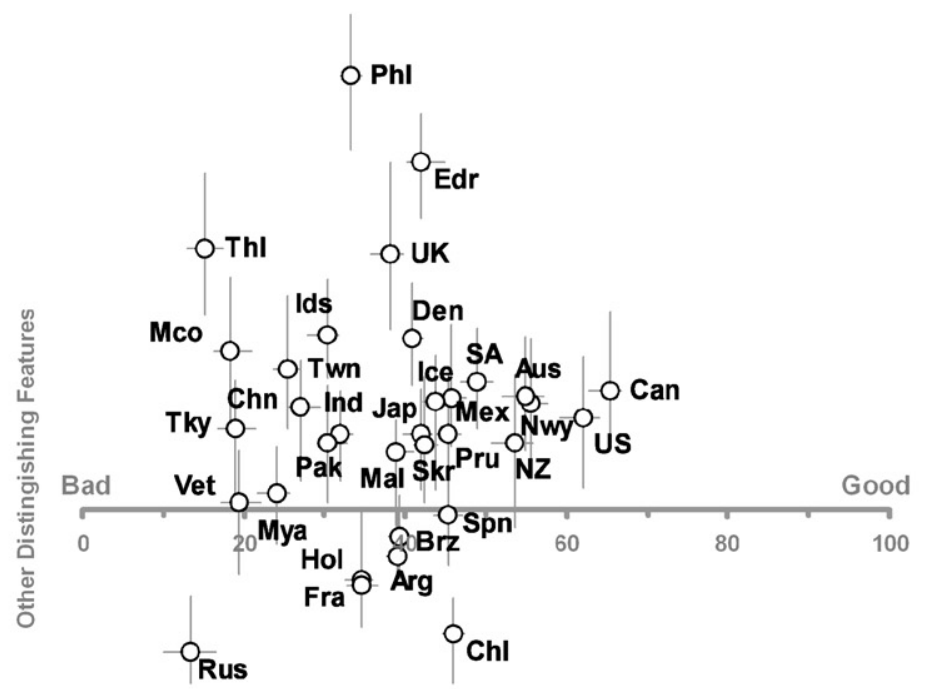

EBFM Implementation Steps Performance Score, \%

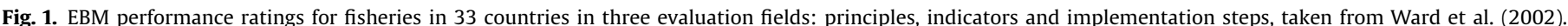

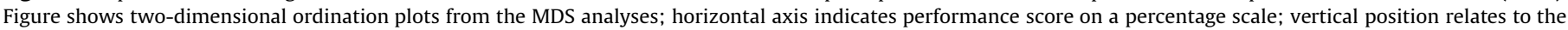

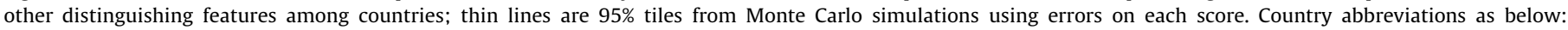

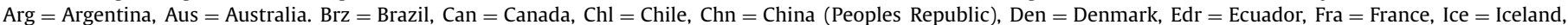

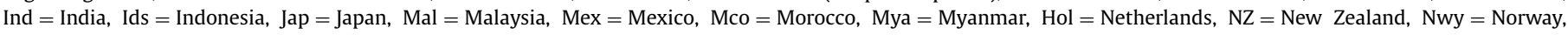

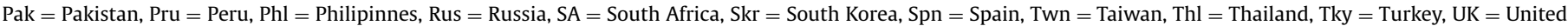
Kingdom, US $=$ United States of America, Vet $=$ Viet Nam.

‘fail grades' of $40 \%$ and less (UK, Argentina, France, India, China, Brazil, Pakistan, Indonesia, Taiwan, Morocco, Turkey, Viet Nam, Myanmar, Russia and Thailand).

\subsection{Test cases}

Fig. 3 shows the results from the test cases plotted on twodimensional ordinations against a background of the overall final results from Fig. 1. It is evident that the EBM performance rating for New South Wales fisheries is some 10-15\% lower than fisheries managed by the Australian Commonwealth. As all Australian fisheries share similar features, we see only small differences on the vertical axis between New South Wales and Australian Commonwealth fisheries.
In all three cases, the Raja Ampat ratings of today's performance in EBM are not significantly different from the overall Indonesian value along the EBM performance axis. Unsurprisingly, there are, however, large differences the vertical axis that express differences between this small region of Papua and Indonesia as a whole. Fig. 3 also shows our projections of what ratings Raja Ampat might achieve if the present EBM plans were to be fully implemented.

\section{Discussion: the challenge of implementing EBM worldwide}

The comparison of Indonesian scores for Raja Ampat and the overall values for Indonesia, which were independently arrived at, show similarities that provide encouraging validation for the 

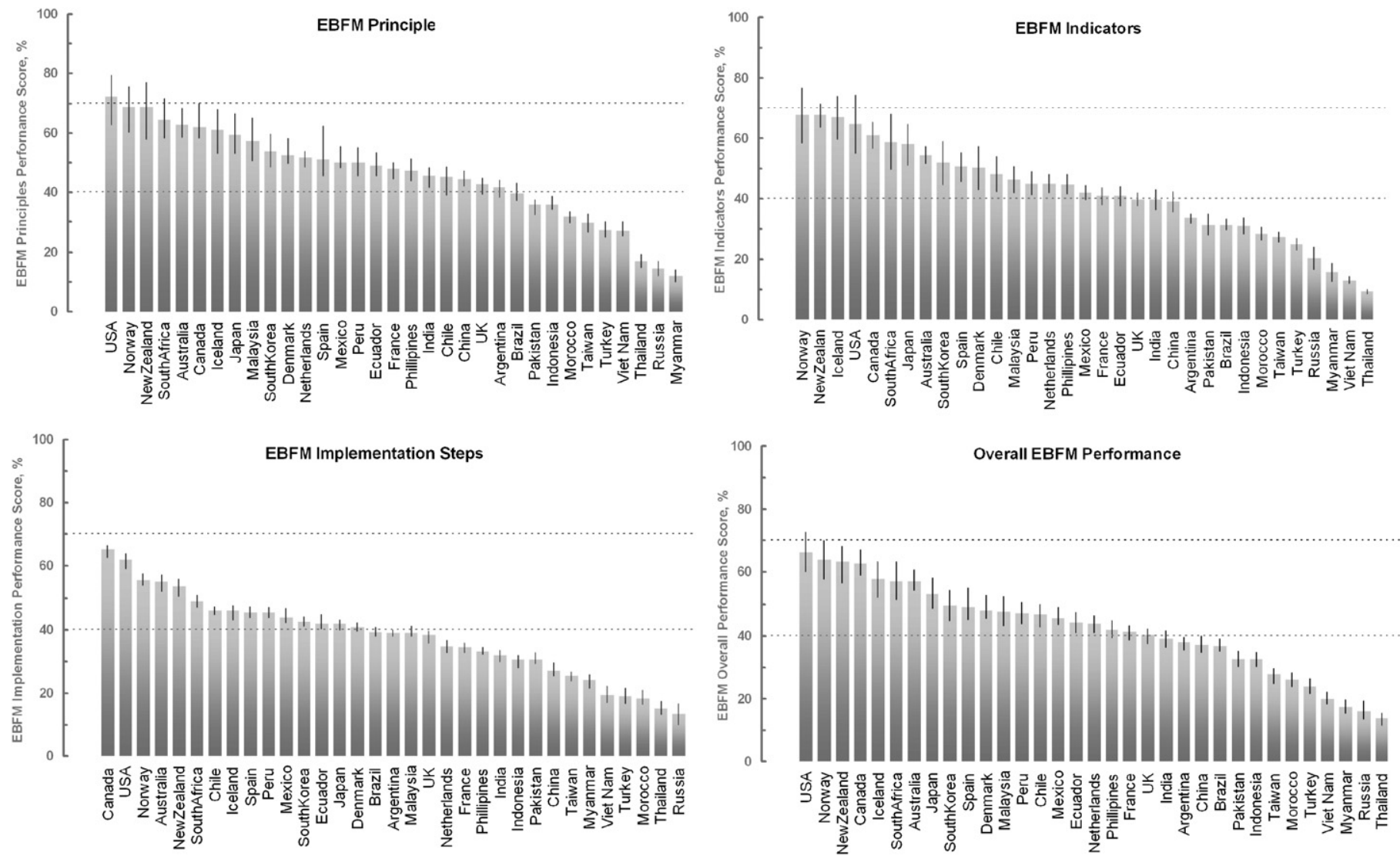

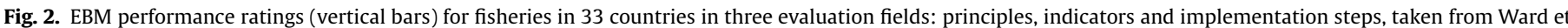

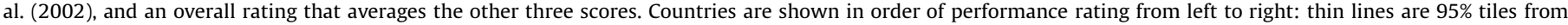

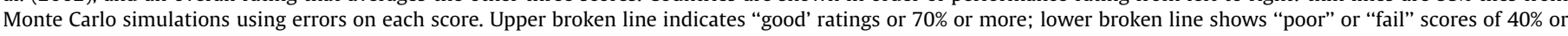
lower.

method. Moreover, vertical axis results, expressing differences among fisheries, are also encouraging for the method. For example, there are only small differences on the vertical axis between New South Wales and Australian Commonwealth fisheries. Although Indonesia falls in the lower quartile of "fail" grades overall, Fig. 3 shows that the Raja Ampat region of Papua might achieve EBM ratings as high as the top five developed countries if present plans were to be successfully and fully implemented.

Most countries achieved lower ratings for Indicators than for EBM principles (evaluation field 2: 22/33); while almost all countries had lower ratings for implementation steps (evaluation field 3: 30/33). This finding is not surprising as it is easier to publish good intentions for EBM principles than to actually achieve the tangible steps towards EBM scored in evaluation field 3. On average ratings were $9.7 \%$ lower for implementation steps. One country, Myanmar, went significantly against this trend by having $12 \%$ higher performance on implementation steps, presumably reflecting the difficulty in finding any published principles for this country, as opposed to documented brave conservation efforts by a few individuals.

One of the EBM implementation steps has especially low scores in our analysis. "Setting up training courses in EBM for fishers and managers" averages only 1.0/10 (1.3 standard deviations below the mean), while 19/33 countries score zero. This 'training course' action would likely be a final implementation step in EBM, so that only countries that have already moved some way towards EBM will be able to achieve a reasonable score. Two other low-scoring questions are the "implementation of ecological risk assessment" (average 2.7/10; 7 countries with 0 ), and "strategies agreed among all stakeholders" (average 2.9/10: 7 countries with 0 ).

Our analysis reveals that only a few countries in the developed world are clearly moving towards EBM, but it is most interesting that several developing countries rank above their more developed neighbours (e.g., Malaysia, Peru, Mexico, Ecuador and South Africa), especially in Field 1 covering EBM Principles even if their ratings on Field 3, implementation steps, are generally lower. This may represent the actions of a few brave and progressive fishery legislators and managers in these countries and the more community-based nature of local fisheries management. Indeed, moving towards participatory fisheries management is a key aspect for success in implementing EBM. Many developing countries recognise that, in spite of some achievements towards the implementation of such approach, there is a need for capacitybuilding through awareness and direct technical assistance to help build their national capacity for the task [20].

Notable among the EBM scores are the dismal ratings of many developed European countries in spite of the Common Fisheries Policy undergoing an ecosystem-based reform in 2002. This can be seen graphically as a long horizontal cluster of high Human Development Index (HDI) countries to the left of the highestranking countries in Fig. 4. Despite academic excellence, widespread awareness of the issues and policy work emphasising the need to move towards EBM, to date it does not seem to have led to much clear regulation or action to implement tangible actions. Some may speculate on the reasons for this lamentable inertia among developed countries that undoubtedly have the resources for implementation. Bianchi et al. [20] suggest that such failures 


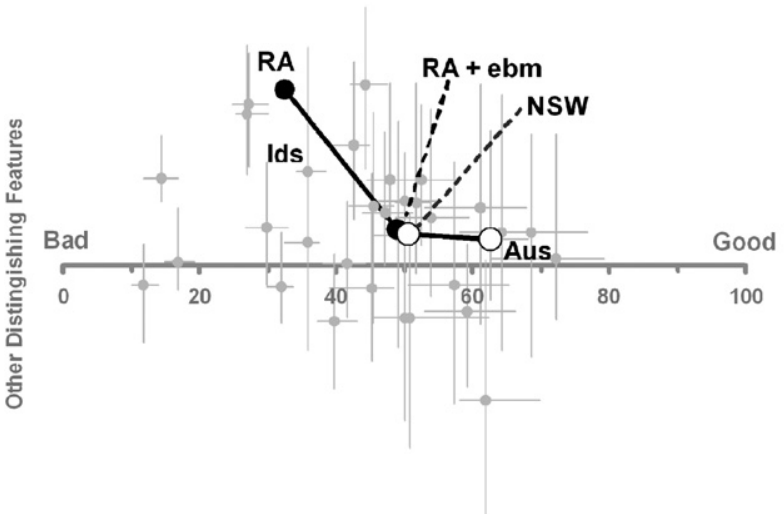

EBFM Principles Score, \%

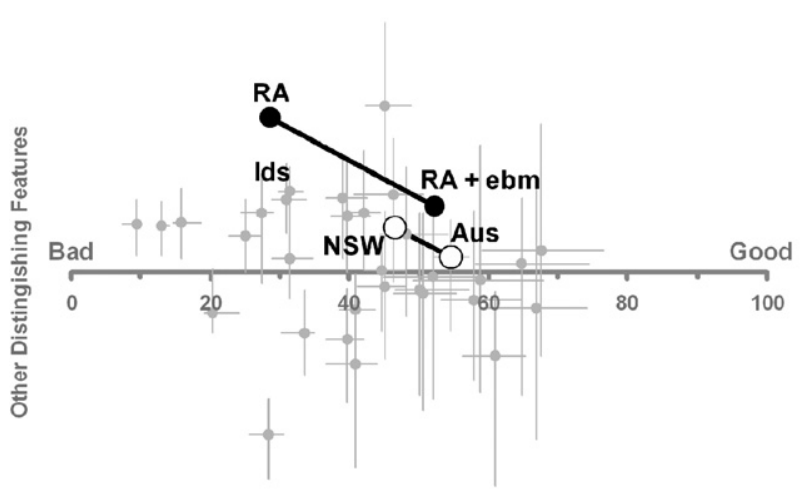

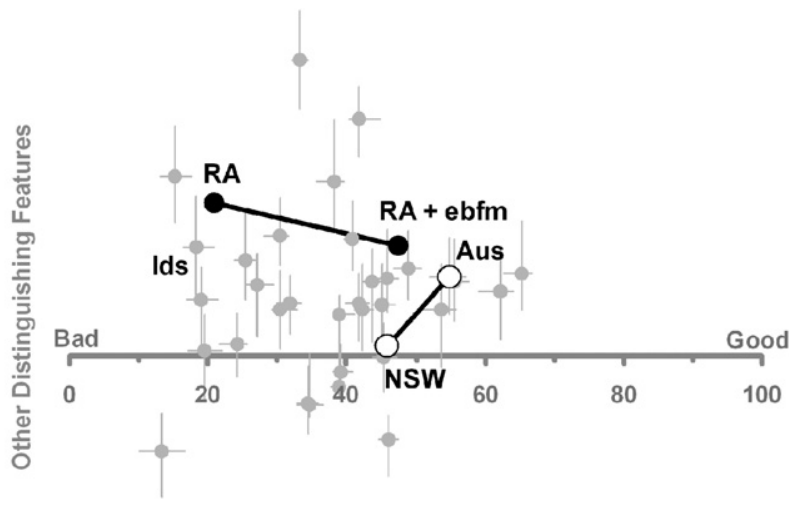

EBFM Implementation Steps Performance Score, \%

EBFM Indicators Performance Score, \%

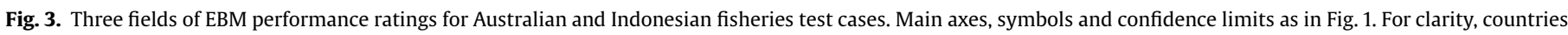

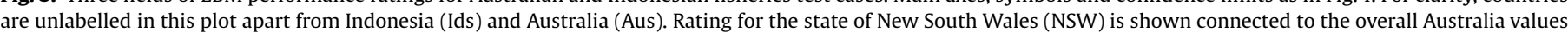

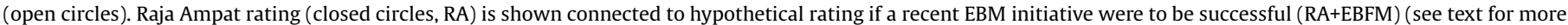
details).

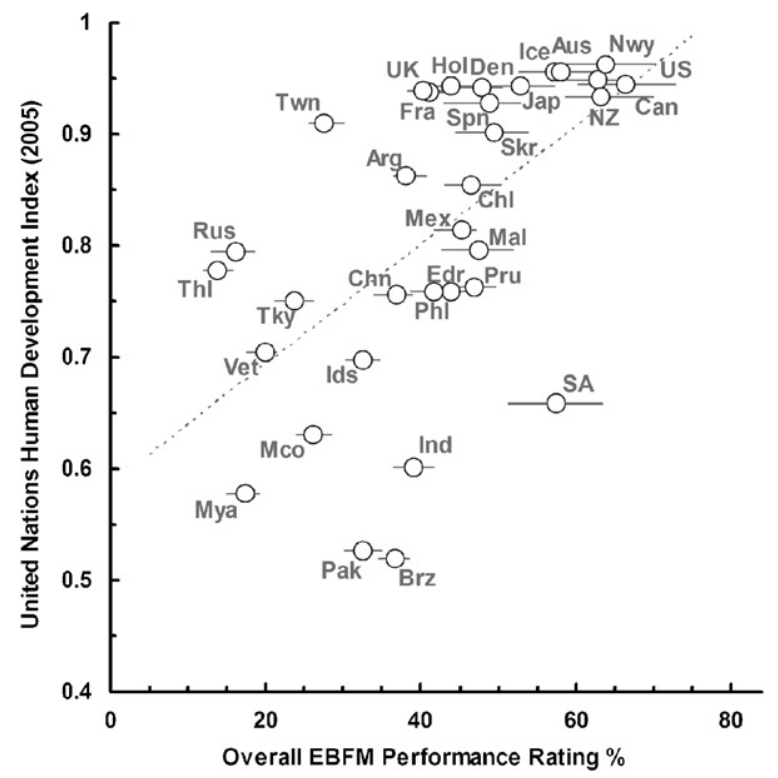

Fig. 4. Plot of United Nations Human Development Index for 33 countries (2005 data) against estimated overall EBM performance ratings. Thin horizontal bars are 95\% limits of EBM values. Broken line: regression of HDI on EBM; sig at 99\% level; $\mathrm{COD}=0.29^{* * *}$. may result from responding piecemeal to specific international agreements, advocacy pressure, trade requirements or immediate crises and not as a result of the development of a comprehensive, EBM plans for all fisheries in an ecosystem. EBM is increasingly recognised as providing the principles and methodology for areabased management or marine spatial planning for all maritime users. Whilst the late nineties also saw the blossoming of 'Oceans' approaches aimed at developing and applying EBM principles to multiple sectors in multi-stakeholder processes, the gradual pace of these reforms and their perceived expense has meant that few have been implemented. The South East Regional Marine Plan in Australia and the Benguela Current Commission are the two successful examples. What is evident, however, is that these processes are needed to implement comprehensive marineprotected area networks and to restructure fisheries, and this remains a key political challenge.

Our analysis is based on the jurisdictional role of countries, while an alternative approach would focus on the undoubtedly differing performances of individual fisheries in achieving EBM, but this approach would take a lot of resources to develop a global picture. Overall, however, our EBM performance ratings correlates quite well with UN Human Development Index (HDI, Fig. 4), although the correlation is not a strong one $(\mathrm{COD}=0.29 \%, P<0.01)$. This creates a considerable challenge for international agencies, governments and NGOs that wish to encourage the adoption of EBM. 


\section{References}

[1] US Commission on Ocean Policy. An ocean blueprint for the 21st century. Final report of the USA Commission on Ocean Policy to the President and Congress, Washington, DC, USA, 2004.

[2] Hall SJ, Mainprize B. Towards ecosystem-based fisheries management. Fish and Fisheries 2005;5:1-20.

[3] Pikitch EK, Santora C, Babcock EA, Bakun A, Bonfil R, Conover DO, et al. Ecosystem-based fishery management. Science 2004;305:346-7.

[4] Hilborn R, Punt AE, Orensanz J. Beyond band-aids in fisheries management: fixing world fisheries. Bulletin of Marine Science 2004;74(3):493-507.

[5] Brodziak J, Link J. Ecosystem-based fishery management: what is it and how can we do it? Bulletin of Marine Science 2002;70(2):589-611.

[6] FAO. Code of conduct for responsible fisheries. Rome: FAO; 1995. p. 41

[7] FAO. The ecosystem approach to fisheries. FAO technical guidelines for responsible fisheries, vol. 4 (Suppl. 2). Rome: FAO; 2003. p. 112

[8] Collie J, Gislason H. Biological reference points for fish stocks in a multispecies context. Canadian Journal of Fisheries and Aquatic Sciences 2001;58:2167-76.

[9] Caddy JF, Mahon R. Reference points for fisheries management. FAO Fisheries Technical Paper, vol. 347, 1995, 83p.

[10] Link J. Translating ecosystem indicators into decision criteria. ICES Journal of Marine Science 2005;62:569-76.

[11] Rice JC. Evaluating fishery impacts using metrics of community structure. ICES Journal of Marine Science 2000;57:682-8.

[12] Ward T, Tarte D, Hegerl E, Short K. Policy proposals and operational guidance for ecosystem-based management of marine capture fisheries. World wide fund for nature. Sydney, Australia, 2002, 80p. (Although developed by WWF Australia, this framework is an WWF International fisheries policy paper).
[13] Pitcher TJ, Kalikoski D, Pramod G, editors. Evaluations of compliance with the UN code of conduct for responsible fisheries. Fisheries Centre research reports, vol. 14(2), 2006, 1191. Also available at: 〈http://www.fisheries.ubc ca/publications/reports/report14_2.php $>$.

[14] Coremap. Penelitian Terumbu Karang Tingkat Lokal, Kab. Raja Ampat, Provinsi Irian Jaya Barat. Sekretariat COREMAP Tahap II WB, Dinas Perikanan dan Kelautan, Kab. Raja Ampat, Indonesia, 2005, p. 75 (in Bahasa).

[15] Ainsworth CH, Varkey DA, Pitcher TJ. Ecosystem simulation models of Raja Ampat, Indonesia, in support of ecosystem-based fisheries management (pp. 3-124). In: Pitcher BM, Pitcher TJ, editors. Ecological and economic analyses of marine ecosystems in the birds head seascape, Papua, Indonesia: II. Fisheries Centre research reports, vol. 16 (1) 2008, 186p.

[16] Varkey D, Pitcher TJ, Ainsworth CH. Ecosystem based management: the influence of a project in Raja Ampat, Papua, Indonesia (pp. 165-175). In: Pitcher BM, Pitcher TJ, editors. Ecological and economic analyses of marine ecosystems in the birds head seascape, Papua, Indonesia: II. Fisheries Centre research reports, vol. 16 (1), 2008, 186p.

[17] Kruskal JB, Wish M. Multidimensional scaling. Beverley Hills, CA, USA: Sage Publications; 1978.

[18] Pitcher TJ, Preikshot DB. Rapfish: a rapid appraisal technique to evaluate the sustainability status of fisheries. Fisheries Research 2001;49(3): 255-70.

[19] Kavanagh P, Pitcher TJ. Implementing microsoft excel software for rapfish: technique for the rapid appraisal of fisheries status. Fisheries Centre research reports, vol. $12(2), 2004,75$ p.

[20] Bianchi G, Cochrane KL, Vasconcellos M. Implementing the ecosystem approach to fisheries. In: Wrammer P, editor. Fish, trade and development. Royal Swedish Academy of Agriculture and Forestry, 2008, (in press). 